\title{
Editorial: ASAP Ten Years On
}

\author{
John Stillwell ${ }^{1}$
}

Received: 30 January 2017 / Accepted: 31 January 2017 /

Published online: 6 February 2017

(C) Springer Science+Business Media Dordrecht 2017

This is the first issue of Applied Spatial Analysis and Policy (ASAP) as it enters its tenth year of existence, a period over which the journal has grown quite rapidly in terms of both the number of manuscripts submitted and the number of papers published, particularly following recognition by the Institute for Scientific Information (ISI) in 2013. Manuscript submissions increased from 39 in 2013 to 141 in 2016, with a resulting drop in the acceptance rate from 59\% of submissions in 2013 to $27 \%$ in 2016. Volume 1 of ASAP in 2008 included 11 papers totalling 242 pages in three issues; ten years on, we are planning for Volume 10 to comprise approximately 28 papers across 600 pages in four issues. The content of the journal has been very diverse with, for example, special issues devoted to Poverty and Deprivation Mapping, Demographic and Economic Change in Northern England, Internal Migration, Planning Support Systems, Urban Futures and Modelling Urban Behaviour.

The average number of days to final acceptance has been reduced from 320 to 246 over the last three years and we have widened the international scope of the journal significantly. In 2015, for example, out of the 47 papers published in the four e-issues, eight were from the United Kingdom, five from Italy, four from each of Australia, Sweden and the USA, three each from Canada, China, Malaysia and The Netherlands, two each from Finland and Taiwan and one each from Belgium, Germany, Iran, Mexico, Poland and Spain.

Journal impact factors are published each summer by Thomson Reuters and reflect the yearly average number of citations of papers published in a journal for a particular year compared with the number of papers published in the same journal in the previous two years. The two-year impact factors for ASAP for 2013, 2014 and 2015, and the numbers of citations and papers from which the factors are derived, referred to as source items, are shown in Fig. 1. The ratios of citations to papers underline the need to ensure that, as the journal increases the number of papers it publishes, these papers have impact and are cited by authors publishing in other journals.

John Stillwell

geo6jchs@leeds.ac.uk

1 School of Geography, University of Leeds, Leeds LS2 9JT, UK 


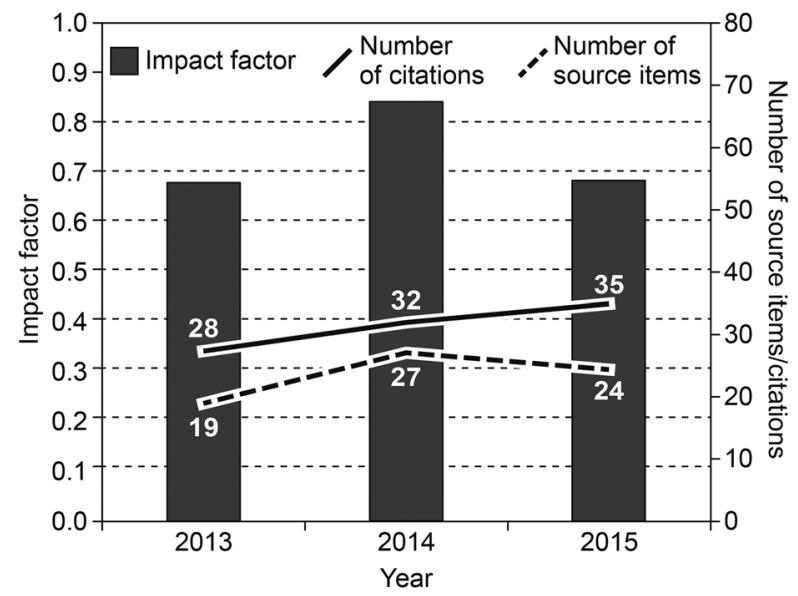

Fig. 1 ASAP's impact factor: number of citations and source items, 2013-2015

The development of $A S A P$ has not happened without a huge amount of effort freely offered by members of the editorial team and the journal's many reviewers in different countries across the world to whom we express heartfelt gratitude. I do not recall a single paper that has been accepted for the journal without some measure of revision and almost all authors have responded very positively to either minor or major revisions that have been recommended, indicating on many occasions much appreciation for the helpful comments and careful guidance for improvement that have resulted in eventual acceptance.

So, as ASAP enters its tenth year and we contemplate further growth in submissions and workloads, the time is appropriate for a change of personnel. Initially we planned for this refresh to occur after three years, but it never managed to take place. My colleague at Leeds, Mark Birkin, has stepped down from his role as Co-editor in Chief and I am very grateful to Mark for his wise counsel and support over many issues over the last decade, not least his help in getting the journal launched in the first instance. I am very pleased to welcome Paul Norman and Adam Dennett as his replacements and look forward to working together with them over the next three years.

Nik Lomax has taken over from Andy Evans as the journal's Book Reviews Editor, whilst Dave Maguire and Paul Waddell are standing down as Associate Editors; Guy Engelen and Keiji Yano are moving from being Associate Editors to become Editorial Board members. Anne Green, Ye Liu and Ed Manley have joined the team as Associate Editors and Guy Abel, Jonathan Corcoran, Lex Comber, Eric Koomen, Chris Lloyd, Bruce Newbold, Jacques Poot and Dianna Smith have agreed to join the Editorial Board, replacing Antoine Bailly, Mike Batty, Gunter Haag, Marek Kupiszewski, Denise Pumain, Mike Sanderson, David Simmonds, Grant Thrall, Waldo Tobler and Nigel Waters.

I are very grateful for the contributions of those who have supported ASAP thus far and those who have agreed to give their assistance over the coming years to ensure that the journal goes from strength to strength. 